\title{
Relationship between eNOS gene polymorphism and cerebral infarction of young and middle-aged Chinese Han population
}

\author{
Hu H, Huang Y, Jiang L, Yangn MJ, Xu SY, Wang YM, Hu ZP \\ Department of Emergency, Shanghai Huashan Hospital Affiliated to Fudan University, Shanghai, P. R. China. \\ zupenghu2013@63.com
}

\begin{abstract}
Purpose: To discuss the relationship between the acute cerebral infarction of differently aged population and the variable number tandem repeat polymorphism of endothelial nitric oxide synthase (eNOS) gene. Methods: The genotypes of 129 acute cerebral infarction patients and 100 healthy control subjects were determined by PCR and polyacrylamide gel electrophoresis (PAGE).

Results: In the patient group, the frequency of allelic gene a was higher than that in the control group (13.56\% vs $3 \%, p<0.01$ ), and the frequencies of the patients followed the descending order from young through middle-aged to elderly ( $42.31 \%$ vs $17.2 \%$ vs $5.8 \%$ ). The frequencies of the young, middle-aged and elderly population in the control group differed significantly (5.55\% vs $2.94 \%$ vs $2.63 \%$ ), and those of the young and middle-aged population in the two groups also differed statistically significantly.

Conclusion: The ab genotype of eNOS 4th intron is correlated with the acute cerebral infarction of young and middle-aged Chinese Han population that may involve allelic gene a as an independent risk factor (Tab. 3, Fig. 3, Ref. 13). Text in PDF www.elis.sk.

Key words: young and middle-aged population, acute cerebral infarction, endothelial nitric oxide synthase, gene polymorphism.
\end{abstract}

Acute cerebral infarction (ACI), as a common and frequently occurring disease, is one of the major diseases that seriously threat the health and life of human beings and recently even young people. Scholars worldwide have proposed gene detection concerning susceptible groups by studying multiple gene polymorphisms to prevent and control the occurrence of cerebral infarction $(1,2)$. Endothelial nitric oxide synthase 3 (Nos3) gene, which is located in human chromosome $7 \mathrm{q} 36$ with the length of about $22 \mathrm{~kb}$, includes 26 exons and 25 introns mainly existing in vascular endothelial cells, and its catalysate eNO can inhibit the adhesion and aggregation of platelets and leukocytes on vascular endothelial surface, and proliferation of vascular smooth muscle cells. Therefore, Nos 3 is an important inhibitory factor of atherosclerosis. The variable number tandem repeat sequence (VNTR) polymorphism of 27 bases of intron 4 is closely related to the level of plasma nitric oxide (NO). The correlation of this polymorphism with cardiovascular and cerebrovascular disease has been thoroughly studied, but the conclusions differ significantly between geographies and ethnics (3). This study aims to explore the relationship between eNOS gene polymorphism and young and middle-aged cerebral infarction in Chinese Han population.

Department of Emergency, Shanghai Huashan Hospital Affiliated to Fudan University, Shanghai, P. R. China

Address for correspondence: ZP Hu, Department of Emergency, Shanghai Huashan Hospital Affiliated to Fudan University, Shanghai 200040, P. R. China.

\section{Materials and methods}

\section{Subjects}

129 Han Chinese patients with ACI who received emergency diagnosis in our hospital from January 2009 to April 2011 were selected, of which there were 75 males and 54 females. The patients were divided into three subgroups according to the aged-grading method of the World Health Organization (WHO): young group (14-44 years old; $n=13)$, middle-aged group (45-65 years old; $n=$ 47 ) and elderly group (over 65 years old; $n=69$ ). Age and gender were matched in the control group. All selected subjects underwent examinations on blood pressure, blood sugar and cholesterol.

Inclusion criteria: The ACI group underwent cranial MRI or CT scan to confirm the diagnosis, while meeting the diagnostic criteria of Sonntag et al (4). Cerebral hemorrhage and space-occupying lesions were excluded. The patients of the control group had no history of stroke.

\section{Materials}

Data collection

Unified information registration form was design to collect the related information on patients that were admitted in emergency. The demographic information included name, gender, age, age of onset, onset symptoms, cranial CT or MRI results and disease history.

\section{Sample collection}

The ACI patients admitted in emergency in whom atrial fibrillation, tumor and blood system diseases were excluded, and CT or 


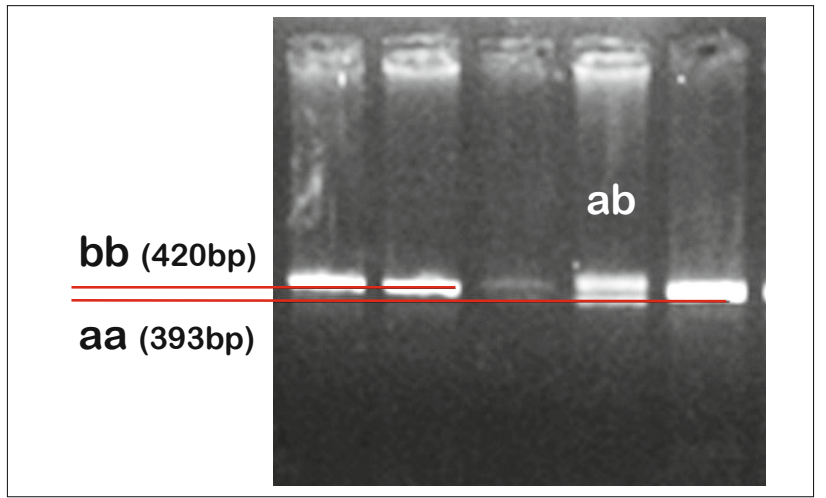

Fig. 1. Detection of PCR results.

MRI results showed clear infarction were included in this study. After informed consent, $2 \mathrm{ml}$ of cubital venous blood was drawn, anti-coagulated with EDTA-K2t and stored in refrigerator at $4{ }^{\circ} \mathrm{C}$.

Extraction of blood genomic DNA

Blood genomic DNA was extracted using a centrifugal column genomic DNA extraction kit (TIANGEN, DP318) and the samples were stored at $-80{ }^{\circ} \mathrm{C}$.

\section{Reaction system}

VNTR polymorphism of eNOS gene intron 4: the primers were synthesized by Shanghai Institute of Biological Engineering with reference to the method of Wang et al (1). The upstream and downstream primers were 5'-AGGCCCTATGGTAGTGCCTTT-3' and 5'-TCTCTTTAGTGCTGTGGTCAC-3', respectively. Reaction system: $2 \mu \mathrm{l}$ of DNA template, $8.5 \mu \mathrm{l}$ of $\mathrm{ddH}_{2} \mathrm{O}, 1 \mu \mathrm{l}$ of upstream primer, $1 \mu \mathrm{l}$ of downstream primer and $12.5 \mu \mathrm{l}$ of $2 \times$ Taq polymerase; $25 \mu \mathrm{l}$ in total. PCR reaction conditions: initial denaturation at $95^{\circ} \mathrm{C}$ for $3 \mathrm{~min} \rightarrow$ denaturation at $95^{\circ} \mathrm{C}$ for $45 \mathrm{~s} \rightarrow 58^{\circ} \mathrm{C}$ for $30 \mathrm{~s} \rightarrow 72{ }^{\circ} \mathrm{C}$ for $30 \mathrm{~s}$ for 35 cycles in total $\rightarrow$ extension $72^{\circ} \mathrm{C}$ for $5 \mathrm{~min}$. The PCR products were stored at $4{ }^{\circ} \mathrm{C}$.

PCR product detection

$10 \mu \mathrm{l}$ of PCR amplification product was taken to be mixed with $2 \mu \mathrm{l}$ of loading buffer for $3 \%$ agarose gel electrophoresis at $100 \mathrm{~V}$ for $100 \mathrm{~min}$. Photographs were taken for observation by the UV gel imaging system (Fig. 1).

\section{Statistical analysis}

The genotype of each individual sample was read, genotype and allele frequencies were calculated, and sample group representation was confirmed in accordance with the Hardy Weinberg equilibrium
Tab. 1. General information of the two groups $(x \pm s)$.

\begin{tabular}{lccc}
\hline Item & ACI & Control & $\mathrm{p}$ \\
\hline Gender $(\mathrm{F} / \mathrm{M})$ & $54 / 75$ & $44 / 56$ & $>0.05$ \\
Age & $65.23 \pm 14.55$ & $62.68 \pm 16.82$ & 0.35 \\
SBP $(\mathrm{mmHg})$ & $155.37 \pm 15.78$ & $149.63 \pm 16.23$ & 0.18 \\
DBP $(\mathrm{mmHg})$ & $92.34 \pm 12.15$ & $87.67 \pm 9.36$ & 0.26 \\
TC (mmol/L) & $5.21 \pm 0.89$ & $4.69 \pm 0.88$ & 0.23 \\
TG (mmol/L) & $2.18 \pm 0.68$ & $1.99 \pm 0.54$ & 0.071 \\
Fasting BG (mmol/L) & $7.51 \pm 0.71$ & $6.83 \pm 0.66$ & 0.087 \\
BMI & $26.1 \pm 2.3$ & $24.8 \pm 2.3$ & 0.31 \\
Smoking history (n, \%) & $37(28.7 \%)$ & $22(22 \%)$ & $>0.05$ \\
\hline
\end{tabular}

Tab. 2. eNOS4 genotypes and allelic gene frequencies in the two groups.

\begin{tabular}{lcccccc}
\hline \multirow{2}{*}{ Group } & \multirow{2}{*}{$\mathrm{n}$} & \multicolumn{3}{c}{ Genotype } & \multicolumn{3}{c}{ Allelic gene frequency } \\
\cline { 3 - 7 } & & $\mathrm{a} a$ & $\mathrm{ab}$ & $\mathrm{bb}$ & $\mathrm{a}$ & $\mathrm{b}$ \\
\hline Control & 100 & $0(0.00)$ & $6(6)$ & $94(94)$ & $6(3)$ & $194(97)$ \\
ACI & 129 & $1(0.78)$ & $33(25.58)$ & $95(73.64)$ & $35(13.56)$ & $223(86.44)$ \\
\hline
\end{tabular}

Chi-square results comparison, $\mathrm{p}<0.01$.

principle. The data were analyzed using SPSS16.0 and the numeration data between groups were compared using the Chi-square test.

\section{Results}

\section{Risk factors of the two groups}

There were no significant differences in age, gender, body mass index, SBP, DBP, smoking history, total cholesterol (TC) and triglycerides (TG) between the ACI group and control group (Tab. 1).

\section{Gene distributions of the two groups}

The aa, ab and bb types in the control group were $0 \%, 6 \%$ and $94 \%$, respectively and in the ACI group they were $0.78 \%$, $25.58 \%$ and $73.64 \%$, respectively. The a and $\mathrm{b}$ allele frequencies were $13.56 \%$ and $86.44 \%$, respectively in the ACI group and $3 \%$ and $97 \%$, respectively in the control group. The a allele frequency was higher in the ACI group than in the control group $(\mathrm{p}<0.01)$ (Tab. 2).

Gene distributions of young, middle-aged and elderly subgroups in the ACI group

The aa, $\mathrm{ab}$ and bb types accounted for $0 \%, 11.11 \%$ and $88.89 \%$, respectively in the young group, $2.13 \%, 68.09 \%$ and $29.79 \%$, respectively in the middle-aged group and $0 \%, 88.41 \%$ and $11.59 \%$, respectively in the elderly group. The a and $b$ allele frequencies were $42.31 \%$ and $67.69 \%$, respectively in the young group, $17.02 \%$ and $82.98 \%$, respectively in the middle-aged group and $5.80 \%$ and $94.20 \%$, respectively in the elderly group. The a allele fre-

Tab. 3. eNOS4 genotypes and allelic gene frequencies of the young, middle-aged and elderly subgroups in the ACI group.

\begin{tabular}{|c|c|c|c|c|c|c|c|}
\hline \multirow{2}{*}{ Group } & \multirow{2}{*}{ Age } & \multirow{2}{*}{$\mathrm{n}$} & \multicolumn{3}{|c|}{ Genotype } & \multicolumn{2}{|c|}{ Allelic gene } \\
\hline & & & aa & $\mathrm{bb}$ & $\mathrm{ab}$ & $\mathrm{a}$ & $\mathrm{b}$ \\
\hline Young & $37.31 \pm 4.17$ & 13 & 0 & $2(11.11)$ & $11(88.89)$ & $11(42.31)$ & 15 (67.69) \\
\hline Middle-aged & $56.19 \pm 5.05$ & 47 & $1(2.13)$ & $32(68.09)$ & $14(29.79)$ & $16(17.02)$ & 78 (82.98) \\
\hline$\underline{\text { Elderly }}$ & $76.65 \pm 6.35$ & 69 & 0 & $61(88.41)$ & $8(11.59)$ & $8(5.80)$ & $130(94.20)$ \\
\hline
\end{tabular}

Chi-square results comparison, $\mathrm{p}<0.01$. 


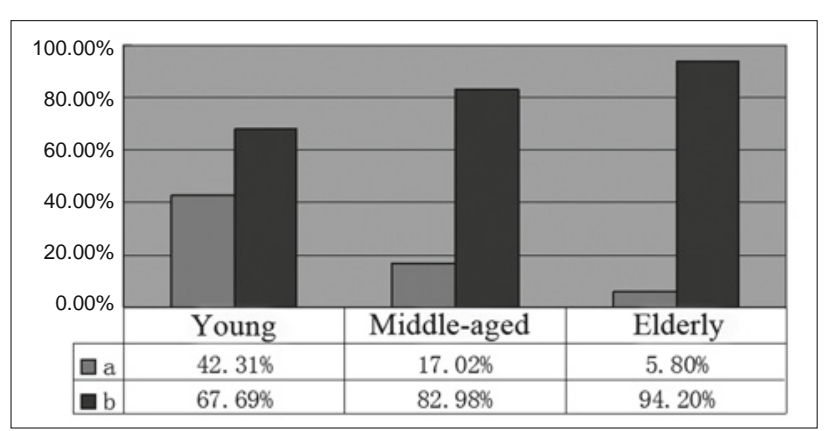

Fig. 2. Gene distributions of young, middle-aged and elderly subgroups in the ACI group.

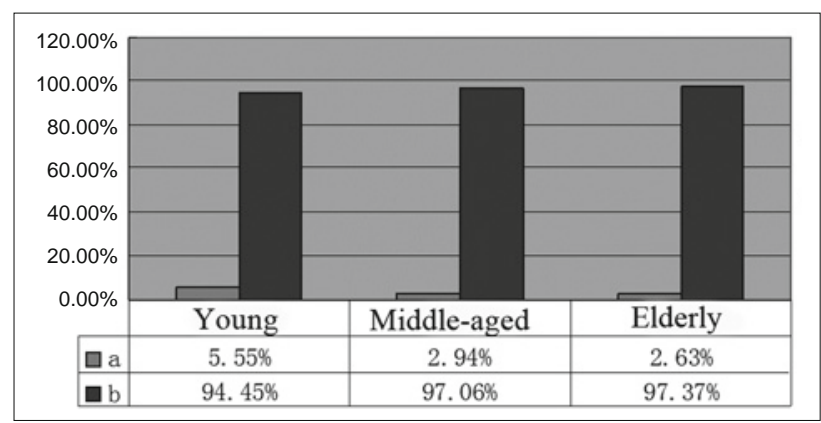

Fig. 3. Gene distributions of young, middle-aged and elderly subgroups in the control group.

quencies followed the descending order from young group through middle-aged group to elderly group (Tab. 3).

\section{Gene distributions of young, middle-aged and elderly subgroups in the two groups}

The Chi-square test results of allele frequency for the ACI group and the control group of the young group was $0.01<\mathrm{p}$ $<0.05, \mathrm{p}<0.01$ for the middle-aged group and $\mathrm{p}>0.05$ for the elderly group. In the youth and middle-aged groups, the a allele frequencies were higher in the ACI group than those in the control group, but in the elderly group, no significant differences were found between the two groups (Figs 2 and 3).

\section{Discussion}

The eNOS gene is located in human chromosome $7 \mathrm{q} 35 \sim \mathrm{q} 36$ region, with the length of about $22 \mathrm{~kb}$, including 26 exons and 25 introns. Its encoded mRNA containing 4025 nucleotides is a single copy in the haploid human genome. So far, 5 polymorphism sites of eNOS gene have been found, namely 3 single nucleotide polymorphisms (SNPs), 1 tandem repeat polymorphism of different number and 1 dinucleotide repeat polymorphism (5). The 27bp insertion/deletion $(\mathrm{a} / \mathrm{b})$ polymorphism exists in eNOS intron 4. There are two alleles according to the different repeat number of $27 \mathrm{bp}$, which repeats four times is a allele and five times b allele, so as to constitute three genotypes (aa, ab, bb). The eNOS gene 27bpVNTR polymorphism genotyping accounts for different proportion in different ethnics and geographies. Li et al. conducted detection on 60 healthy African Americans, and the result showed that aa, ab and bb types accounted for $14.5 \%, 27.5 \%$ and $58 \%$, respectively (6). Huang et al studied 68 cases of healthy Han Chinese living in Fujian, and found that $\mathrm{aa}$, $\mathrm{ab}$ and bb types accounted for $0 \%, 10.3 \%$ and $89.7 \%$, respectively (7). In this study, the aa, $\mathrm{ab}$ and $\mathrm{bb}$ types of 100 healthy controls accounted for $0 \%, 6 \%$ and $94 \%$, respectively, which varies greatly from the proportion of genotypes in foreign Caucasian, while it is basically consistent with the genotypes in the Southern Han Chinese. The a allele frequencies of eNOS gene differ a lot, which is $26.5 \%$ in African Americans, $16.0 \%$ in Caucasians and $12.9 \%$ in Asians (8). Uwabo et al reported that $\mathrm{a}$ and $\mathrm{b}$ allele frequencies were $10.2 \%$ and $89.8 \%$, respectively in 413 healthy Japanese (9). The a allele frequency of eNOS gene was $3 \%$ in 100 healthy Han Chinese, which was lower than those of the Asian Africans and Japanese.

The eNOS gene polymorphism may affect the function of eNOS, resulting in the change of the concentration of NO in the vascular system, and thus affecting the occurrence and development of atherosclerosis, so it may be associated with coronary heart disease and ischemic cerebrovascular disease. The correlation between variation of eNOS gene in different locations with cardiovascular and cerebrovascular disease is different. Hou et al. conducted a study on Chinese people, and confirmed that intron 4 gene polymorphism of eNOS may be an independent risk factor for ischemic cerebrovascular disease in Chinese people, which is particularly significant in patients suffering from ischemic cerebrovascular disease however with no common risk factors (10). Munshi et al. found that VNTR polymorphism of eNOS gene is significantly correlated with the occurrence of ischemic stroke in South Indian people (11). The relationship between eNOS gene polymorphism and coronary heart disease and ischemic cerebrovascular disease has been confirmed by many scholars internationally, but there are also differences. Yahashi et al (12) studied the relationship between this gene polymorphism and ischemic stroke in the Japanese, and found that the $b$ allele frequency ratio of 127 patients (including 18 cases of thromboembolism, 58 cases of lacunar infarction and 51 cases of asymptomatic lacunar infarction) to 91 normal controls was $0.862 / 0.868$, and the ratio of allele frequencies in ischemic stroke subgroups was $0.889 / 0.862 / 0.853$, with the difference not statistically significant. MacLeod et al. (13) conducted relevant research on the G894T polymorphism of eNOS gene exon 7 in 361 ischemic stroke patients and 236 control subjects, and found no difference in NN genotype distribution between the two groups, suggesting that this polymorphism is not correlative with atherosclerotic cerebral infarction and TIA.

This study found that the ab genotype frequency and a allele frequency of the ACI group were significantly higher than those of the control group after excluding the impact of risk factors such as age, blood pressure, blood sugar, blood lipid and smoking, etc. In the subgroups of different ages, it was found that the allele frequency of ACI patients was as in a descending order from young group, through middle-aged group to elderly group, which had a significant correlation with age, but there was no such a distribution in the control group. This indicates that eNOS gene polymorphism may be an independent risk factor for the occurrence of ACI in the 
young and middle-aged Chinese Han, with significant correlation with age. This result is consistent with what Hou et al has reported, which provides further evidence that eNOS gene VNTR polymorphism is correlative with ischemic stroke in Chinese population.

\section{References}

1. Fu Y, Ni P, Ma J, Ying Y, Zhao J, Liu J et al. Polymorphisms of human vascular endothelial growth factor gene are associated with acute cerebral infarction in the Chinese population. Eur Neurol 2011; 66: 47-52.

2. Kang WY, Wang HL, Xiong LF, Wang XF, Chu HY, Qu B et al. Polymorphisms of the coagulation factor VII gene and its plasma levels in relation to acute cerebral infarction differences in allelic frequencies between Chinese Han and European populations. Chin Med J (Engl) 2004; 117: 71-74.

3. Wang XL, Mahaney MC, Sim AS et al. Genetic cont ribution of the endothelial constitutive nit ric oxide synthase gene to plasma nit ric oxide levels. Arterioscler Thromb Vasc Biol 1997; 17 (11): 3147-3153.

4. Sonntag WE, Eckman DM, Ingraham J, Riddle DR. Regulation of Cerebrovascular Aging. In: Brain Aging: Models, Methods, and Mechanisms. Edited by Riddle DR. Boca Raton (FL); 2007.

5. Xiong L, Hu M, Zhang X, Jing Z, Li T, Li G et al. Association between Glu298Asp/677C-T single nucleotide polymorphism in the eNOS/ MTHRF gene and blood stasis syndrome of ischemic stroke. Gene 2012; 511: 475-479.
6. Li R, Lyn D, LapuBula R et al. Relation of endothelial nitric oxide synthase gene to plasma nitric oxide level, endothelial function, and blood pressure in African Americans. Am J Hypertens 2004; 17 (7): 560-567.

7. Bin HH, Hong L, Qin CM. Endothelial nitric oxide synthase gene and essential hypertension polypeptide of the relationship between type 2 diabetes Endocrinology and Metabolism 2002; 18 (1): 16-19.

8. Tanus-Santos JE, Desai M, Flokhart DA. Effects of ethnicity on the distribution of clinically relevant endothelial nitric oxide variants. Pharmacogenetics 2001; 11 (8): 719-725.

9. Uwabo J, Soma M, Nakayama T et al. Association of avariable number of tandem repeat $\mathrm{s}$ in the endothelial constitutive nit ric oxide synthase gene with

10. Hou L, Osei Hyiaaman D, Yu H et al. Association of a 27-bp repeat poly-morphism in ecNOS gene with ischemic stroke in chinese patients. Neurology 2001; 56 (4): 490-496.

11. Munshi A, Rajeshwar K, Kaul S et al.VNTR polymorphism in intron 4 of the eNOS gene and the risk of ischemic stroke in a South Indian population. Brain Res Bull 2010; 82 (5-6): 247-250.

12. Yahashi Y, Kario K, Shimada K et al. The $272 \mathrm{bp}$ repeat polymorphism in intron 4 of the endothelial cell nitric oxide synthase gene and ischemic stroke in a Japanese population. Blood Coagul Fibrinolysis 1998; 9 (5): 405-409.

13. MacLeod MJ, Dahiyat MT, Cumming A et al. No association between Glu /Asp polymorphism of NOS3 gene and ischemic stroke. Neurology 1999; 53 (2): 418-420. 